\title{
Short- and long-term effects of hemodialysis on platelet and monocyte activity markers of atherosclerosis in patients with end-stage renal disease
}

\author{
Urs Benck ${ }^{1}$, Ksenija Stach ${ }^{2}$, Susanne Jung ${ }^{2}$, Bernhard K. Krämer ${ }^{1}$, \\ Thorsten Kälsch ${ }^{3}$, Anna-Isabelle Kälsch ${ }^{1}$ \\ ${ }^{1} 5^{\text {th }}$ Medical Department, University Medical Centre Mannheim, \\ Medical Faculty Mannheim, University of Heidelberg, Germany \\ ${ }^{2} 1^{\text {st }}$ Medical Department, University Medical Centre Mannheim, \\ Medical Faculty Mannheim, University of Heidelberg, Germany \\ ${ }^{3}$ Heart Centre Weinheim, University Medical Centre Mannheim, \\ Medical Faculty Mannheim, University of Heidelberg, Germany
}

\begin{abstract}
Background: In hemodialysis (HD) patients cardiovascular events represent the predominant cause of mortality. Since platelet and monocyte activity markers play an important role in cardiovascular mortality, this study assessed the influence of HD on these markers.

Methods: Forty one HD patients (25 male, 16 female) were included. Blood samples were obtained before and after a single HD session at baseline and again after an elapsed period of $114 \pm 21$ days (91-175 days) on maintenance hemodialysis. Surface expression of CD40L and CD62P on platelets, tissue factor binding on monocytes and platelet-monocyte aggregates were measured by flow cytometry. Plasma levels of monocyte chemotactic protein-1 (MCP-1), interleukin-6 (IL-6), tumor necrosis factor alpha $(T N F \alpha)$ and soluble CD40L were analyzed by enzyme linked immunosorbent assay.

Results: Tissue factor on monocytes was significantly increased after a single HD session at baseline $(p=0.041)$, whereas platelet-monocyte aggregates, the expression of CD40L and CD62P on platelets did not change significantly. After a mean of $114 \pm 21$ days of HD therapy, tissue factor on monocytes $(p<0.0001)$, platelet-monocytes aggregates $(p<0.0001)$, plasma levels of MCP-1 $(p=0.012)$ and $T N F \alpha(p=0.046)$ were significantly decreased compared to baseline values. In contrast, platelet surface expression of CD4OL and CD62P as well as plasma levels of SCD4OL and IL-6 were not attenuated significantly. There was no significant correlation detected between the markers examined and the cumulative time on hemodialysis.

Conclusions: Platelet and monocyte activity markers assessed in this study do not appear to be signifcantly increased by HD therapy. Therefore, these markers probably cannot be accountable for increased cardiovascular mortality in chronic HD patients. (Cardiol J 2018; 25, 5: 595-600)
\end{abstract}

Key words: platelets, monocytes, hemodialysis, atherosclerosis

\section{Introduction}

Despite renal replacement therapy using hemodialysis (HD), end-stage renal disease (ESRD) is associated with increased cardiovascular morbidity and mortality, mainly due to cardiovascular events. HD therapy aims to reduce renal morbidity and overall mortality in ESRD patients. However, as-

Address for correspondence: Thorsten Kälsch, MD, Heart Centre Weinheim University Medical Centre Mannheim, Medical Faculty Mannheim, University of Heidelberg, Theodor-Kutzer-Ufer 1-3, 68167 Mannheim, Germany, tel/fax: 0049-16099180775/0049 6214006213, e-mail: t.kaelsch@yahoo.de 
sociations between mortality and the dialysis dose applied have been studied with negative results in patients on maintenance dialysis $[1,2]$.

Prevalent complications in patients with chronic kidney diseases are alterations in hemostasis, which correlate with the progressive loss of renal function to ESRD. Both, bleeding diathesis and thromboembolic events have been identified in ESRD patients and increased circulating inflammatory proteins predict a worse prognosis $[3,4]$. Plasma levels of coagulation factors are normal to elevated in these patients. Therefore, the occurrence of hemorrhagic events is mainly a result of platelet dysfunction [5]. Efficient hemostasis requires the secretion of several adhesive substances by platelets, as well as adhesion and aggregation of platelets at the site of vascular injury [6]. In ESRD impaired platelet adhesiveness as well as abnormal interactions between platelets and the endothelium yields altered platelet function [7]. Despite appropriate anticoagulation during HD, uremic toxins and the increased platelet activation may contribute to altered platelet function in ESRD patients [8]. In the development of atherosclerosis interaction between activated platelets and endothelial cells plays an crucial pathophysiologic role [9]. In detail, these interactions mediate the development of atherosclerosis by an increased expression of vascular cell adhesion molecules and their ligands. These include P-selectin, an $\alpha$-granule protein that mediates platelet rolling, leukocyte adhesion and coagulation, tissue factor expression on monocytes, platelet-monocyte-aggregates, and $\mathrm{CD} 40 \mathrm{~L}$, a member of the tumor necrosis factor alpha $(\mathrm{TNF} \alpha)$ family of proteins [10]. CD40L and CD62P are expressed on activated platelets and are directly involved in the interaction of platelets with monocytes and endothelial cells [11].

Cardiovascular events related to thrombosis account for an excessive mortality in chronic HD patients [12]. In this respect the CD40 receptor and its ligand (CD40L) on activated platelets are of particular interest. They are known to modulate both inflammation and thrombosis, which promote the development of clinical atherosclerosis [13]. Tissue factor expression on monocytes is important in extrinsic coagulation and elevated in HD patients compared to healthy controls [14].

Whether ESRD itself or chronic HD therapy over and above is responsible for these alterations in hemostasis and the consecutively elevated cardiovascular mortality is still unclear. Thus, in order to investigate possible procoagulatory effects of HD on established markers of atherosclerosis,
Table 1. Study population.

\begin{tabular}{lc}
\hline & $\begin{array}{c}\text { Hemodialysis } \\
\text { patients }(\mathbf{n}=41)\end{array}$ \\
\hline Age [years] & $61.83 \pm 15.42$ \\
Male & $25(61 \%)$ \\
Hyperlipoproteinemia & $6(15 \%)$ \\
Coronary artery disease & $12(29 \%)$ \\
Peripheral arterial disease & $8(20 \%)$ \\
Diabetes mellitus & $15(37 \%)$ \\
Hypertension & $35(85 \%)$ \\
\hline
\end{tabular}

Table 2. Medication in use.

\begin{tabular}{lc}
\hline Medication & $\begin{array}{c}\text { Hemodialysis } \\
\text { patients (n = 41) }\end{array}$ \\
\hline ASA & $5(12 \%)$ \\
Anti-coagulants & $9(22 \%)$ \\
Beta-blocker & $22(54 \%)$ \\
CSE-inhibitor & $4(10 \%)$ \\
ACEl/AT(1) antagonist & $20(49 \%)$ \\
\hline
\end{tabular}

ACEI - angiotensin converting enzyme inhibitor; ASA - acetylsalicylic acid

the present study assessed the short and long-term effects of HD on platelet and monocyte activity markers of atherosclerosis.

\section{Methods}

\section{Study population and protocol}

For this prospective longitudinal study 41 HD patients (25 male, 16 female) were included consecutively. Patient characteristics and baseline medication are displayed in Tables 1 and 2 .

In order to investigate short- and long-term effects of HD on markers of atherosclerosis, tissue factor binding on monocytes, platelet-monocytesaggregates, and platelet surface expression of $\mathrm{CD} 40 \mathrm{~L}$ and $\mathrm{CD} 62 \mathrm{P}$ were measured at the beginning and the end of a single HD session (time A) and again after a mean of $114 \pm 21$ days (91-175 days) (time $\mathrm{B}$, at the beginning of the HD session).

Plasma concentrations of TNF $\alpha$, interleukin- 6 (IL-6), monocyte chemotactic protein-1 (MCP-1) and soluble CD40L were determined at baseline (time A) and again after a mean of $114 \pm 21$ days (91-175 days) (time B).

The investigation conforms to the principles outlined in the Declaration of Helsinki. The study was approved by the local ethics committee and all 
patients gave informed consent to the use of their medical record for research purposes.

Patients were hemodialyzed with hollow-fiber polysulfone membrane dialysators with a $1.2 \mathrm{~m}^{2}$ surface area $(n=40)$ (Polysulfon UF 4.0; Haemoflow F5, Fresenius, Germany) or with a cellulose triacetate dialysator ( $\mathrm{n}=1)(\mathrm{CT} 150 \mathrm{G}$, Baxter, Germany) with bicarbonate-containing solutions for $13.2 \mathrm{~h}$ (range 9-20 h) weekly. All the patients were advised to comply with a chronic renal failure diet consisting of 35 $\mathrm{kcal} / \mathrm{kg}$, including $1.2-1.4 \mathrm{~g} / \mathrm{kg}$ of protein, $1000-1500$ $\mathrm{mg}$ of calcium, $700 \mathrm{mg}$ of phosphorus and $250 \mathrm{mg}$ of magnesium, vitamins and recombinant human erythropoietin. The Kt/V was assessed once for each $\mathrm{HD}$ patient at the beginning of the study at timepoint A. The mean $\mathrm{Kt} / \mathrm{V}$ was $1.53 \pm 0.28$. Patients were on HD for 47.78 months (range 2-157 months) at the time of entry to the study. All patients were routinely dialysed 3 days per week.

\section{Flow cytometric analysis}

Blood samples of heparinized blood (15 IE heparin per ml blood) (Sarstedt AG \& Co/Nuembrecht, Germany) were obtained. To avoid procedural aggregation and activation of platelets, the blood samples were shaken over the time. All whole blood samples were subsequently investigated on activation of monocytes and platelets as well as platelet binding on monocytes.

Flow cytometric analysis of platelets was performed by gating in forward and side scatter. Platelets were gated back for determination of the expression of CD40L and CD62P. Platelet-monocyte aggregates were measured by CD41 (GPIIb/IIIa receptor) surface expression on platelets adherent to monocytes.

For the analysis of platelets, $100 \mu \mathrm{L}$ of each whole blood sample was stained for $30 \mathrm{~min}$ at room temperature with $10 \mu \mathrm{L}$ aliquots of mouse anti-human CD62P-PE antibodies (CLB-Thromb/6) (Coulter Immunotech/Krefeld, Germany) and mouse anti-human CD40L-FITC antibodies (P2) (Calbiochem/Merck KGaA, Darmstadt, Germany). For the analysis of monocytes, $100 \mu \mathrm{L}$ of each whole blood sample were stained for $30 \mathrm{~min}$ at room temperature with $10 \mu \mathrm{L}$ aliquots of PE-conjugated murine antibody against CD41 (Coulter Immunotech/ Krefeld, Germany) and murine FITC-conjugated antibody against tissue factor (American Diagnostica/Pfungstadt, Germany). To identify monocytes, the probes were additionally stained with mouse anti-human CD14-ECD (RM052) (Coulter Immu-
notech/Krefeld, Germany). Isotype matched mouse anti-human IgG1 PE/FITC antibodies (Beckman Coulter/Marseille, France) were used as a control. After incubation, erythrocytes were lysed with $500 \mu$ L Optilyse C (Coulter Immunotech/Krefeld, Germany). After $15 \mathrm{~min}$, cells were resuspended in $500 \mu \mathrm{L}$ phosphate buffered saline and were then ready for flow cytometric analysis. For measurement of CD40L and CD62P on platelets, a gating for forward and sideward scatter was performed. For measurement of CD41 on platelets adherent to monocytes to determine platelet-monocyteaggregates and for assessment of membrane bound tissue factor a gating for the monocyte surface antigen CD14 and sideward scatter was performed. All flow cytometric analysis was performed on an EPICS XL-MCL analyzer (Beckman Coulter, Krefeld, Germany) equipped with an argon laser tuned at $488 \mathrm{~nm}$. Compensation of the four-channel fluorescence was precisely adjusted using CytoCompTM reagents and Cyto-TrolTM control cells (Coulter Immunotech/Krefeld, Germany).

\section{Enzyme linked immunosorbent assay (ELISA)}

Plasma concentrations of TNF $\alpha$ (Human $\mathrm{TNF} \alpha / \mathrm{TNFSF} 1 \mathrm{~A}$ Immunoassay R\&D Systems, Inc., Wiesbaden, Germany), IL-6 (Human IL-6 Immunoassay R\&D Systems, Inc., Wiesbaden, Germany), MCP-1 (Human MCP-1/CCL2 Immunoassay R\&D Systems, Inc., Wiesbaden, Germany), soluble CD40L (Human soluble CD40 Ligand Immunoassay R\&D Systems, Inc., Wiesbaden, Germany) were determined by sandwich-type immunoassay according to the manufacturer's instructions. All concentration analysis was performed on an ELISA-Reader - Lab Systems Multiskan RC (Lab systems, Finland). Genesis Lite Software, ELISA Multiskan RC was used for data acquisition and evaluation.

\section{Statistical analysis}

Numerical data were expressed as mean \pm standard deviation (SD). A Mann-Whitney test was applied as a nonparametric test. Categorical variables were analyzed using a $\chi^{2}$ test and t-test. Values are expressed as mean values \pm SD. A twotailed probability $<0.05$ was considered significant. All calculations were performed using GraphPad InStat version 3.01 (GraphPad Software, San Diego, California, USA) and SPSS Statistics version 17 (SPSS-Software GmbH, Munich, Germany). 


\section{Results}

Influence of a single hemodialysis session on markers of atherosclerosis

Tissue factor binding on monocytes significantly increased during the dialysis session (before dialysis: $1.32 \pm 0.29$; after dialysis: $1.43 \pm 0.4$; $\mathrm{p}=0.041$, Fig. 1). Regarding the amount of platelet-monocyte aggregates (before dialysis: $19.3 \pm$ \pm 10.44 ; after dialysis: $21.08 \pm 15.23 ; \mathrm{p}=\mathrm{NS}$ ) and platelet surface expression of CD40L (before dialysis: $5.25 \pm 1.68$; after dialysis: $5.07 \pm 1.14$; $\mathrm{p}=\mathrm{NS}$ ) and CD62P (before dialysis: $1.91 \pm 0.93$; after dialysis: $1.92 \pm 1.29$; $\mathrm{p}=\mathrm{NS}$ ), there was no significant difference between the values before and after the dialysis session (time A).

\section{Long-term effect of hemodialysis on markers of atherosclerosis}

Tissue factor binding on monocytes (time A: $1.32 \pm 0.29$; time B: $0.99 \pm 0.22 ; \mathrm{p}<0.0001 ;$ Fig. 2 ) and platelet-monocytes aggregates (time A: $19.3 \pm$ \pm 10.44; time B: $10.53 \pm 4.16$; p < 0.0001; Fig. 3 ) were significantly decreased between time $A$ and $B$. No significant change was observed in respect of platelet surface expression of CD40L (time A: $5.25 \pm 1.68$; time B: $5.34 \pm 1.16 ; \mathrm{p}=\mathrm{NS}$ ) and CD62P (time A: $1.91 \pm 0.93$; time B: $1.81 \pm 0.66$; $\mathrm{p}=\mathrm{NS}$ ) between time A and time $\mathrm{B}$.

\section{Long-term effect of hemodialysis on chemokines}

Plasma levels of TNF $\alpha$ significantly decreased over time (time A: $9.25 \pm 11.13 \mathrm{pg} / \mathrm{mL}$; time B: $4.87 \pm 2.44 \mathrm{pg} / \mathrm{mL} ; \mathrm{p}=0.046$; Fig. 4$)$, as well as plasma levels of MCP-1 (time A: $327.84 \pm 157.86$ $\mathrm{pg} / \mathrm{mL}$; time B: $288.89 \pm 157.87 \mathrm{pg} / \mathrm{mL} ; \mathrm{p}=0.012$; Fig. 5). Plasma levels of IL-6 (time A: $5.12 \pm 3.61$ $\mathrm{pg} / \mathrm{mL}$; time B: $5.57 \pm 3.84 \mathrm{pg} / \mathrm{mL} ; \mathrm{p}=\mathrm{NS}$ ) and sCD40L (time A: $459.9 \pm 722.85 \mathrm{pg} / \mathrm{mL}$; time B: $234.53 \pm 324.6 \mathrm{pg} / \mathrm{mL} ; \mathrm{p}=\mathrm{NS}$ ) did not change significantly over time.

Correlation between dialysis duration and markers of atherosclerosis and chemokines

No significant correlation was found between the time on dialysis and tissue factor on monocytes $(r=-0.026 ; \mathrm{NS})$, platelet-monocytes aggregates $(r=0.042 ; \mathrm{NS}), \mathrm{CD} 40 \mathrm{~L}(\mathrm{r}=-0.156 ; \mathrm{NS})$ or $\mathrm{CD} 62 \mathrm{P}$ $(r=-0.231 ; \mathrm{NS})$.

Also, there was no correlation between the time on dialysis and plasma levels of TNF $\alpha$ ( $r=-0.047 ; \mathrm{NS})$, IL-6 ( $\mathrm{r}=0.066$; NS), MCP-1 $(r=0.008 ; \mathrm{NS})$ or $\mathrm{sCD} 40 \mathrm{~L}(\mathrm{r}=-0.002 ; \mathrm{NS})$.

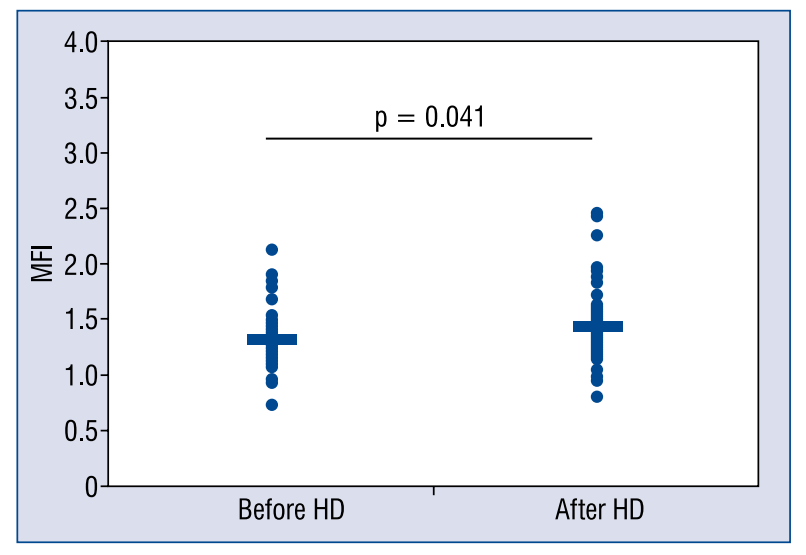

Figure 1. Tissue factor binding on monocytes before and after hemodialysis (HD); MFI - mean fluorescence intensity.

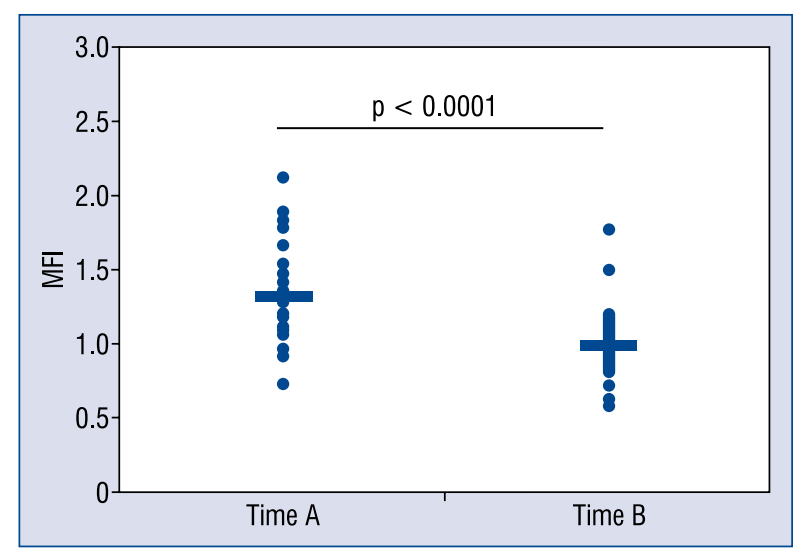

Figure 2. Tissue factor binding on monocytes at time $A$ and time $\mathrm{B} ; \mathrm{MFI}$ - mean fluoroscence intensity.

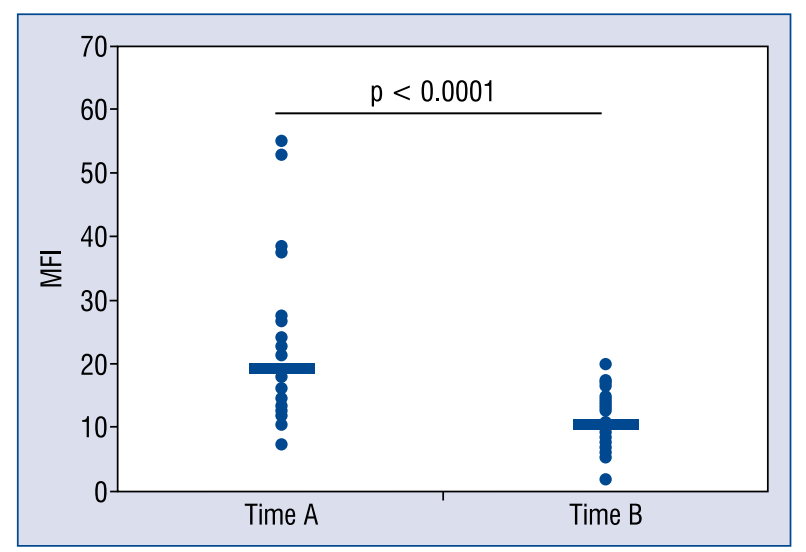

Figure 3. Platelet-monocytes aggregates at time $\mathrm{A}$ and time $\mathrm{B} ; \mathrm{MFI}$ - mean fluorescence intensity. 


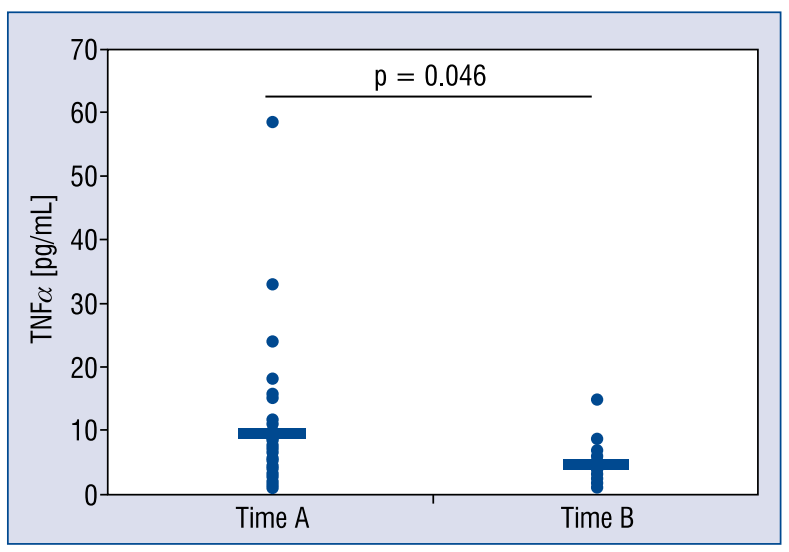

Figure 4. Plasma levels of tumor necrosis factor alpha (TNF $\alpha, \mathrm{pg} / \mathrm{mL}$ ) at time $\mathrm{A}$ and time $\mathrm{B}$.

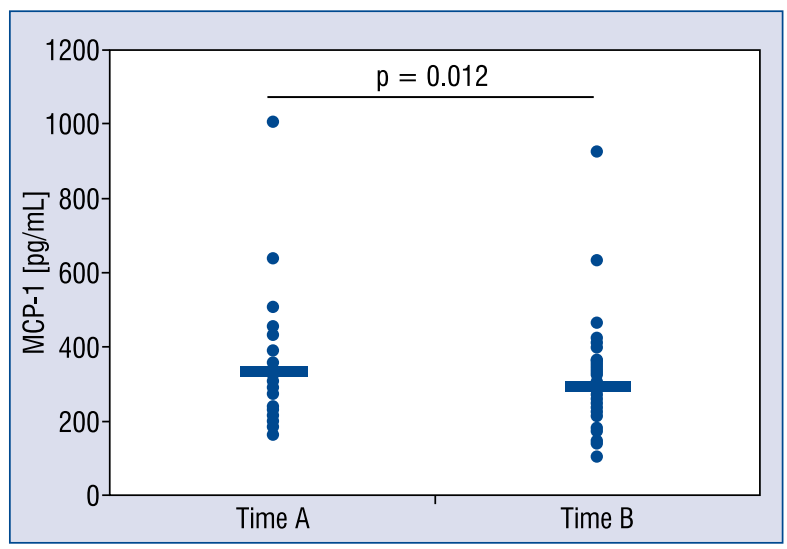

Figure 5. Plasma levels of monocyte chemotactic protein-1 (MCP-1; $\mathrm{pg} / \mathrm{mL}$ ) at time A and time B.

\section{Discussion}

Patients with ESRD undergo renal replacement therapy to avoid fatal complications of uremic toxins, elevated potassium levels and overhydration. Unfortunately, ESRD is accompanied by increased atherosclerotic and thrombembolic morbidity and mortality. Both uremic toxins and the increase of platelet activation irrespective of appropriate anticoagulation during HD may contribute to altered platelet function in ESRD patients [8].

To examine possible short- and long-term effects of the HD itself, a comparison of the expression of platelet and monocyte activity markers and the tissue factor system was done before and after a single HD session and after approximately 4 months of intermittent maintenance HD therapy. During a single dialysis session, a significant increase was revealed in tissue factor on monocytes.
In contrast, tissue factor on monocytes was significantly decreased in the second analysis about 4 months later and showed no overall correlation with the time on dialysis. This might reflect that the activation of tissue factor during the dialysis session is fluctuating and does not persist or accumulate over time.

Tissue factor on monocytes is an important pro-atherogenic marker in these patients since cardiovascular events are closely linked to the tissue factor system [15]. Yorioka et al. [14] described higher levels of tissue factor on monocytes in HD patients in comparison to healthy controls. Al-Saady et al. [16] showed a hypercoagulable state in patients with chronic renal failure as a contributing factor for the increased cardiovascular and cerebrovascular event rate. Consistent with with the presentresults, Kappelmayer et al. [17] described an increase of tissue factor on monocytes during extracorporal circulation.

Kobayashi et al. [18] demonstrated an association between platelet-monocyte aggregates and surrogate parameters of atherosclerosis like brachial-ankle pulse wave velocity and intima media thickness. This argues for a worse effect of platelet-monocyte aggregates in HD patients but it cannot explain why we found a significant decrease after approximately 4 months of HD. Gawaz et al. [19] demonstrated that various dialysis membranes do not influence the formation of platelet-monocyte aggregates.

In contrast to the present findings, Naumnik et al. [20] showed stable MCP-1 levels before and after a HD session, but they did not follow the MCP-1 levels over a longer time period as was done herein. No significant change was observed of MCP-1 levels after a mean HD period of approximately 4 months.

Schwabe et al. [21] demonstrated elevated levels of SCD40L in patients with chronic renal disease in comparison to healthy probands, but Rusu et al. [22] did not reveal an influence of $\mathrm{SCD} 40 \mathrm{~L}$ on survival or cardiovascular events in HD patients in a 108 month follow-up.

Surprisingly, no significant increase was observed in all tested atherosclerotic markers in a second measurement approximately 4 months later. On the contrary, for tissue factor on monocytes, platelet-monocytes aggregates, plasma-level of TNF $\alpha$ and MCP- 1 found a significant decrease over the time period. This might be due to the fact that the initial measurement was not performed at the beginning of the need of renal replacement therapy during the first dialysis and that therefore 
the examined levels might have been high already at the initial measurement. This is underlined by the fact that HD patients had a higher CD62P expression on platelets, a significantly higher amount of platelet-monocyte aggregates, significantly more tissue factor binding on monocytes and significantly higher levels of TNF $\alpha$ compared to peritoneal dialysis patients [23].

\section{Conclusions}

Platelet and monocyte activity markers assessed in this study do not appear to be significantly increased by HD therapy. Therefore, these markers might not be accountable for increased cardiovascular mortality in chronic HD patients.

\section{Conflict of interest: None declared}

\section{References}

1. Eknoyan G, Beck GJ, Cheung AK, et al. Hemodialysis (HEMO) Study Group. Effect of dialysis dose and membrane flux in maintenance hemodialysis. N Engl J Med. 2002; 347(25): 2010-2019, doi: 10.1056/NEJMoa021583, indexed in Pubmed: 12490682.

2. Paniagua R, Amato D, Vonesh E, et al. Mexican Nephrology Collaborative Study Group. Effects of increased peritoneal clearances on mortality rates in peritoneal dialysis: ADEMEX, a prospective, randomized, controlled trial. J Am Soc Nephrol. 2002; 13(5): 1307-1320, indexed in Pubmed: 11961019.

3. Wang AYM, Lam CWK, Wang M, et al. Increased circulating inflammatory proteins predict a worse prognosis with valvular calcification in end-stage renal disease: a prospective cohort study. Am J Nephrol. 2008; 28(4): 647-653, doi: 10.1159/000117817, indexed in Pubmed: 18292652.

4. Sagripanti A, Barsotti G. Bleeding and thrombosis in chronic uremia. Nephron. 1997; 75(2): 125-139, doi: 10.1159/000189522.

5. Evans EP, Branch RA, Bloom AL. A clinical and experimental study of platelet function in chronic renal failure. J Clin Pathol. 1972; 25(9): 745-753, doi: 10.1136/jcp.25.9.745, indexed in Pubmed: 5086216.

6. Gawaz M, Neumann FJ, Dickfeld T, et al. Activated platelets induce monocyte chemotactic protein-1 secretion and surface expression of intercellular adhesion molecule-1 on endothelial cells. Circulation. 1998; 98(12): 1164-1171, doi: 10.1161/01. cir.98.12.1164, indexed in Pubmed: 9743506.

7. Boccardo P, Remuzzi G, Galbusera M. Platelet dysfunction in renal failure. Semin Thromb Hemost. 2004; 30(5): 579-589, doi: 10.1055/s-2004-835678, indexed in Pubmed: 15497100.

8. Schoorl M, Schoorl M, Nubé MJ, et al. Platelet depletion, platelet activation and coagulation during treatment with hemodialysis. Scand J Clin Lab Invest. 2011; 71(3): 240-247, doi: 10.3109/00365513.2011.558106, indexed in Pubmed: 21303224.

9. Libby P, Ridker PM, Maseri A. Inflammation and atherosclerosis. Circulation. 2002; 105(9): 1135-1143, indexed in Pubmed: 11877368.

10. Gawaz M, Brand K, Dickfeld T, et al. Platelets induce alterations of chemotactic and adhesive properties of endothelial cells mediated through an interleukin-1-dependent mechanism. Implications for atherogenesis. Atherosclerosis. 2000; 148(1): 75-85, doi: 10.1016/s0021-9150(99)00241-5, indexed in Pubmed: 10580173.

11. Frenette PS, Johnson RC, Hynes RO, et al. Platelets roll on stimulated endothelium in vivo: an interaction mediated by endothelial P-selectin. Proc Natl Acad Sci U S A. 1995; 92(16): 7450-7454, doi: 10.1073/pnas.92.16.7450, indexed in Pubmed: 7543682.

12. Locatelli F, Vecchio LD, Manzoni C. Morbidity and Mortality on Maintenance Haemodialysis. Nephron. 1998; 80(4): 380-400, doi: $10.1159 / 000045210$.

13. May AE, Kälsch T, Massberg S, et al. Engagement of glycoprotein IIb/IIIa (alpha(IIb)beta3) on platelets upregulates CD40L and triggers CD40L-dependent matrix degradation by endothelial cells. Circulation. 2002; 106(16): 2111-2117, doi: 10.1161/01. cir.0000033597.45947.0f, indexed in Pubmed: 12379582.

14. Yorioka N, Taniguchi Y, Yamashita K, et al. Tissue factor and tissue factor pathway inhibitor in hemodialysis patients. Int J Artif Organs. 1998; 21(11): 699-701, indexed in Pubmed: 9894744.

15. Pawlak K, Pawlak D, Mysliwiec M. Tissue factor and urokinasetype plasminogen activator system are related to the presence of cardiovascular disease in hemodialysis patients. Thromb Res. 2007; 120(6): 871-876, doi: 10.1016/j.thromres.2007.01.011, indexed in Pubmed: 17331567.

16. Al-Saady NM, Leatham EW, Gupta S, et al. Monocyte expression of tissue factor and adhesion molecules: the link with accelerated coronary artery disease in patients with chronic renal failure. Heart. 1999; 81(2): 134-140, doi: 10.1136/hrt.81.2.134, indexed in Pubmed: 9922347.

17. Kappelmayer J, Bernabei A, Edmunds LH, et al. Tissue factor is expressed on monocytes during simulated extracorporeal circulation. Circ Res. 1993; 72(5): 1075-1081, doi: 10.1161/01. res.72.5.1075, indexed in Pubmed: 8097439.

18. Kobayashi S, Miyamoto M, Kurumatani H, et al. Increased leukocyte aggregates are associated with atherosclerosis in patients with hemodialysis. Hemodial Int. 2009; 13(3): 286-292, doi: 10.1111/j.1542-4758.2009.00371.x, indexed in Pubmed: 19583603.

19. Gawaz MP, Mujais SK, Schmidt B, et al. Platelet-leukocyte aggregates during hemodialysis: effect of membrane type. Artif Organs. 1999; 23(1): 29-36, doi: 10.1046/j.1525-1594.1999.06289.x, indexed in Pubmed: 9950176.

20. Naumnik B, Koc-Żórawska E, Myśliwiec M. Over-dialysis plasma RANTES increase depends on heparin dose and cardiovascular disease status. Adv Med Sci. 2013; 58(2): 311-319, doi: 10.2478/ams-2013-0008, indexed in Pubmed: 23959669.

21. Schwabe RF, Engelmann H, Hess S, et al. Soluble CD40 in the serum of healthy donors, patients with chronic renal failure, haemodialysis and chronic ambulatory peritoneal dialysis (CAPD) patients. Clin Exp Immunol. 1999; 117(1): 153-158, doi: 10.1046/j.1365-2249.1999.00935.x, indexed in Pubmed: 10403929.

22. Rusu C, Racasan S, Moldovan D, et al. Soluble CD40 ligand in haemodialysis patients: survival impact and cardiovascular prognostic role. Biomarkers. 2017; 22(3-4): 232-238, doi: 10.1080/1354750X.2016.1201531, indexed in Pubmed: 27295448.

23. Stach K, Karb S, Akin I, et al. Elevation of Platelet and Monocyte Activity Markers of Atherosclerosis in Haemodialysis Patients Compared to Peritoneal Dialysis Patients. Mediators of Inflammation. 2017. https://doi.org/10.1155/2017/8506072. 